\title{
El patrimonio municipal y el impuesto sobre los bienes de las personas jurídicas
}

\author{
por \\ ERNESTO GARCIA ARILLA \\ Secretario del Ayuntamiento de Ejea de los Caballeros
}

El patrimonio municipal ha sido desde antaño motivo de atención para el Fisco, y su mayor o menor presión, quedaba al so. caire de la circunstancia política del momento, o de la conveniencia y oportunidad de encontrar medios con qué mitigar, en parte, la situación deficitaria de los presupuestos del Estado.

La general apatía que los regidores municipales han prodigado en la administración de ese patrimonio, la falta de escrúpulo de algunos vecinos prestos a la usurpación, y la carencia total de apoyo por parte del legislador remiso en dictar disposición expresa que libera los bienes municipales de la acción fiscal, integran, entre otras, las principales causas de su decadencia.

Quizá la consabida dificultad de discernir cuándo un Ayuntamiento actúa como persona jurídica privada o como Corporación de derecho público en todo su inabarcable campo de actividades, ha sido el motivo de que en el ordenamiento legal no aparezca claramente recogida la situación de excepción o sujeción al gravamen de los bienes inmuebles del patrimonio municipal.

A este respecto, las oficinas liquidadoras del impuesto sobre personas jurídicas, vienen promoviendo expedientes de comprobación de valores o practicando liquidaciones por dicho impuesto, que de prosperar como es probable dada la legalidad vigente, harán incurrir, si no lo estaban ya, a muchos Ayuntamientos en situación de solemne pobreza. 
Se pretende por la Hacienda liquidar el referido impuesto, con efectos retroactivos de cinco y hasta de diez años, mediante comprobación como hemos dicho de valores, por ocultación u omisión en las declaraciones, y a base de una investigación o inspección que acarrea la consiguiente liquidación, a la que suman porcentajes de recargos, multas y otros: Las cifras a liquidar son de tal volumen, que para Ayuntamientos de escasa entidad supondrán la ruina, y para los que su patrimonio les permitía ir tirando a trancas y barrancas, la pérdida total de fuerzas económicas para seguir atendiendo las obligaciones mínimas, pero enormes, que sobre el ente municipal pesan.

Nada hay que discutir a la doctrina casi reiterada del Tribunal Económico-administrativo central, que viene denegando reclamaciones de Ayuntamientos sobre exención del impuesto, esgrimiendo por parte de éstos, el carácter de bienes comunales, la desamortización por interés social, o por su destino al uso o servicio público. Pero conviene señalar: ¿Qué Ayuntamiento tiene ajustada a la realidad la valoración de los bienes inmuebles de su patrimonio? Si nos adentramos en la esencia municipal, es muy difícil, prácticamente imposible, que una Corporación local pueda desvirtuar o probar ante el citado Tribunal, que sus bienes reúnen la naturaleza jurídica de comunales y no de propios. Pues, ¿qué patrimonio comunal existe hoy día, por el que no se perciba ingreso alguno? La gratuidad de las prestaciones, explotaciones o servicios municipales, ha quedado relegada como símbolo a Corporaciones de privilegio, que precisamente su minoría justifica la excepción de la regla general.

Lo comunal y gratuito se ha convertido en una fantasía de otros tiempos, que existió, resulta difícil e inasequible aceptarla en nuestros tiempos, donde desde el punto de vista de las facultades o posibilidades económicas municipales, todo, o la mayor parte, es penuria, obligaciones mínimas ineludibles, incremento de servicios, y necesidades perentorias que atender.

¿De qué sirve el que la Ley de Régimen local, inspirada sin duda en lograr para los Ayuntamientos una amplia gama de beneficios fiscales (art. 673 de la vigente), exima del impuesto a que 
aludimos a los bienes comunales, si éstos prácticamente no existen?

¿Cómo se explica, el que el propio Estado estatuya una desgravación de cargas públicas a las Corporaciones locales (véase Ley Régimen local, Disp. adic. $\left.6 .^{a}\right)$, si por otro lado se intenta hacer efectivo el impuesto de persona jurídica y otros, cuya naturaleza y fines son neta y eminentemente estatales?

Conocemos supuestos de Entidades, que desde siempre no habían tributado por el impuesto de personas jurídicas sobre sus bienes, inscritos éstos incluso en el Registro de la Propiedad; y súbitamente se han iniciado y practicado liquidaciones, que superan en algunos casos los dos millones de pesetas por Ayuntamiento, con un gravamen anual de más de 300.000 pesetas.

¿Qué presupuesto municipal aunque su patrimonio sea respetable, hará frente a esta carga del Estado y seguirá afrontando las mismas obligaciones con idéntica fuente de ingresos que tenía con anterioridad?

¿No existe manifiesta contradicción entre estos impuestos del Estado y las disposiciones que promulgan beneficios o subvenciones a los Municipios para que puedan atender servicios obligatorios?

La mejor manera de subvencionar, sería eximir de esas cargas a los Ayuntamientos.

Hay que tener en cuenta, que los aprovechamientos comunales tradicionales que aún subsisten en algunos pueblos, y de los que el vecino se beneficia del cultivo o pasto mediarte el pago de un pequeño o reducido canon, tenderán sin duda alguna a desaparecer, puesto que si la Corporación municipal se ha de resarcir de la contribución territorial, de los gastos de administración, conservación y entretenimiento, del impuesto de personas jurídicas, etcétera, se verá obligada a repercutir y prorratear esos gastos entre los usuarios o concesionarios, de tal forma que el canon supondrá para el vecino tan onerosa contraprestación que se verá asimismo forzado a renunciar a la concesión, con el consiguiente perjuicio económico para el erario municipal; y lo que es más importante, la desaparición de una de las prácticas consuetudinarias de más arraigo y alto espíritu vecinal, como ha sido en la tradi- 
ción española, el típico aprovechamiento de los bienes municipales del común, por medio de reglamentaciones, Ordenanzas o simples usos locales, y mediante el abono de un canon o cuota, o sin él.

El anterior Reglamento del Impuesto de Derechos reales, recogía al menos una exención en su artículo 264-3.o que otorgaba un respiro para aquellos bienes municipales de aprovechamiento comunal procedentes de la desamortización. Esta disposición implicaba la automática exención de los bienes comunales, produjeran o no renta, motivo por el cual han estado la mayoría de esos bienes sin tributar por personas jurídicas, desde siempre, pero la nueva apreciación del Tribunal al considerar de propios todo el patrimonio que produzca renta, ha dado lugar a grandes baches en la Hacienda local. Pero además, como el régimen de impugnación de los expedientes de liquidación del impuesto a que nos referimos, sigue el proceso de la reclamación económico-administrativa por vía ante la Hacienda pública, resulta muy difícil que los Ayuntamientos hagan valer sus argumentos, por otra parte reiterados y conocidos, de intentar la exención por aprovechamiento común, si no prueban a la vez que no perciben renta. Esa directriz olvida completamente que si la contraprestación de tales aprovechamientos, renta o canon, tiene entrada en el estado de ingresos del presupuesto municipal, ¿no es evidente que irán a cubrir los gastos generales de dicho presupuesto, que a la postre no tiene otra finalidad que la de atender necesidades de la comunidad vecinal?

Recientemente la Jurisprudencia del Tribunal Supremo ha sido concluyente. El fallo del Tribunal Económico-administrativo central de 31 de enero del corriente año, sanciona el criterio expuesto de declarar sujetos al impuesto de personas jurídicas, los bienes municipales que no hayan obtenido en forma la exención de la contribución territorial del Estado, reiterando la conceptuación de bienes propios para todos aquellos que produzcan algún beneficio.

Es conocida la dificultad de discernir en la doctrina y en la Ley la naturaleza jurídica de los bienes de propios y comunales. La Audiencia territorial de Zaragoza en sentencia de 25 de marzo de 1961 (Revista Foro Aragonés, epíg. 65) mantiene el crite- 
rio de calificar a los bienes municipales como comunales cuando así nacieron a la vida del derecho, y no sean susceptibles de arrendar o arbitrar, cuestión muy distinta de la percepción de un canon por su aprovechamiento, por medio de una Ordenanza según costumbre o uso local.

Los Decretos de 22 de octubre de 1959 (B. O. del 28) y 26 de abril de 1962 ( $B . O$. del 15 mayo), admiten la existencia y vigencia de los bienes comunales, que superviven a través de los tiempos.

Los artículos 197 de la Ley de Régimen local y 77 del Reglamento de Bienes de 24 de junio de 1955, señalan como fuente legal en el uso y aprovechamiento de los bienes comunales, la costumbre o reglamentación local, pudiendo ser susceptibles de percepción de un canon o cuota.

El artículo 75-2. del susodicho Reglamento, dice al referirse al aprovechamiento de los bienes municipales, que el usuario tendrá que satisfacer en todo caso, un canon no inferior al 16 por $100 \mathrm{del}$ valor en venta de los bienes, y en el extremo 3 de dicho artículo, admite la posibilidad de arrendamiento de los bienes comunales.

Estos criterios que apoyan la exención de impuestos de los bienes comunales, la avala incluso el Tribunal Económico-administrativo central en la sentencia de 26 de enero de 1954 al declarar en su décimotercero considerando que la exención del artículo 264-3.o del Reglamento del Impuesto de Derechos reales y personas jurídicas de 1947, sólo es viable en función de los requisitos: 1. Bienes de aprovechamiento comunal. 2. Que estén exceptuados de la desamortización y no catalogados.

Pese a este precedente las Oficinas liquidadoras continúan liquidando el impuesto a los bienes de aprovechamiento comunal y exceptuados de la desamortización por interés social.

El mismo Tribunal, en fallo de 29 de enero de 1952, dice textualmente: «Que si por el Ayuntamiento reclamante se hubiera acreditado la excepción según el artículo 2. de la Ley de 1 de mayo de 1885 y 11 de julio de 1956, de que son bienes de aprovechamiento común, cosa que podía, y no ha hecho el Ayuntamiento reclamante...» De lo que se infiere, razonando a la inversa, que una vez que se pruebe dicha condición de bienes de aprove- 
chamiento común y exceptuados de la desamortización, debe de otorgarse la exención, independientemente de que esos bienes produzcan o no beneficio alguno.

Entendemos que apremia grandemente el que el legislador ponga fin a ese critero estrictamente fiscal, de considerar la propiedad municipal como bien de propios en todo caso, que los bienes produzcan renta: $\mathrm{Ni}$ esta renta puede equipararse a la de cualquier explotación de un bien particular, ni el destino de aquellos ingresos redundan en beneficio exclusivo o privativo de los miembros, funcionarios, o personal de una Corporación, sino en interés general de toda la comunidad vecinal.

Los bienes comunales que desde su origen son los más, no deben de perder ese carácter por el mero hecho de producir renta, ni en el régimen jurídico del Derecho público y privado, ni dentro del Derecho fiscal, pues son grandes las diferencias que existen con el resto de bienes pertenecientes a otras personas jurídicas privadas, no sólo por cuanto respecta al sujeto del dominio (Corporación de Derecho público), al destino del aprovechamiento, al régimen de explotación o disfrute (repartos entre vecinos cabezas de familia en proporción directa a cargas familiares), sino a la finalidad de sus productos adscritos a sufragar atenciones públicas, y a la cuantía de la contraprestación, canon reducido o cuota, inequiparable a la renta en el régimen privado.

Son escasos los medios legales, pues, con que cuentan los Ayuntamientos para afrontar la situación que les plantea esas liquidaciones del impuesto de personas jurídicas. Coincidiendo con el criterio ajustado y eficaz asesor de las Corporaciones locales del Consultor de los Ayuntamientos, estimamos la necesidad de que debe propugnarse sin dilación un apoyo del Poder público a través de las instituciones políticas, para que con la mayor urgencia se promulgue un precepto con rango jurídico de Ley, en virtud del cual se decida de una vez, el que los bienes de los Ayuntamientos, sea cual fuere su carácter, propios o comunes, están exentos de tributar al Estado por el impuesto de personas jurídicas y hasta por otra clase de impuestos o contribuciones, tanto si esos bienes producen renta como si no, excepto, como es lógico y natural, aquellos bienes sujetos a explotaciones industriales, económicas o si- 
milares. $\mathrm{Y}$ respecto de las situaciones ya consumadas (liquidaciones firmes), que se dejen sin efecto cuantos expedientes se hallen pendientes de liquidación a la fecha de promulgación del precepto, procediendo a la devolución de las cuotas liquidadas por tal impuesto a los Ayuntamientos afectados, con posterioridad a la entrada en vigor del Reglamento del Impuesto de Derechos reales.

De no lograrse así, auguramos verdaderos problemas en el normal desarrollo de aquellos Ayuntamientos que han venido manteniendo un presupuesto no deficitario gracias a los recursos procedentes del escasamente protegido y por muchos caminos acuciado patrimonio comunal. 